\title{
Physical and Chemical Charateristics of Milk. Variation due to Microwave Radiation ${ }^{\dagger}$
}

\author{
Anca Dumuta, ${ }^{*}$ Liviu Giurgiulescu, Leonard Mihaly-Cozmuta, and Zorica Vosgan \\ North University of Baia Mare, 76 Victoriei Street, 430122 Baia Mare, Romania
}

RECEIVED OCTOBER 15, 2010; REVISED DECEMBER 29, 2010; ACCEPTED FEBRUARY 4, 2011

\begin{abstract}
The purpose of this paper was to see what effects microwaves have on the physical-chemical composition of the raw milk. The results showed that the averages of fat, protein, dry substance and lactose concentrations decreased during the microwave exposure while the density averages increased. This variation was characterized by the critical time moment of $31.71 \mathrm{~s}$, corresponding to the moment when a milk sample exposed to the microwaves action undergoes the first more significant alteration of its physical-chemical composition. (doi: 10.5562/cca1785)
\end{abstract}

Keywords: milk, microwaves, Lactoscope FTIR, physical-chemical features, critical point

\section{INTRODUCTION}

Milk and milk products usually undergo different changes during their preparation (boiling and microwaving) or processing, which may include moderate or severe heat treatment that can lead to undesirable changes. Cooking and reheating of foods by microwave ovens are widely used in food preparation in millions of kitchens throughout the world. Food heating by microwave results from the conversion of microwave energy into heat by friction of dipole molecules (water) vibrating due to rapid fluctuation in the electromagnetic filed.

Although the microwave oven is widely used as a means of food preparation, insufficient information is available on the consequences of microwave heating on the composition and nutritional quality of the food. ${ }^{1}$ Valero et al. (1999), mentioned the studies carried out on the effect of microwave treatment on different characteristics of milk: foodborne pathogens, ${ }^{3}$ vitamins, ${ }^{4,5}$ and lactose and whey proteins, ${ }^{6}$ enzymes, ${ }^{7}$ early Maillard products ${ }^{8}$ and cheese making properties. ${ }^{9}$ Also, a review covering several aspects of microwave treatment of milk in domestic ovens has been published. ${ }^{10}$ From all this work it can be concluded that microwave treatment is very effective against microorganisms and that the global composition of microwaved milk is similar to that of conventionally heated milk.

Taking into account that there are relatively few studies about the influence that microwaves have on the composition of the milk, the aim of this study was to investigate if the exposure of the milk samples to the microwaves action for reduced time intervals can generate the alteration of its physical-chemical composition.

\section{EXPERIMENTAL}

The raw cow milk was obtained from a local farm. In order to see what effects microwaves have on its physicalchemical characteristics, 10 samples of $250 \mathrm{ml}$ milk were exposed in unclosed vessels to the microwaves action for each of the following 6 different periods of time: $t_{0}-$ milk samples not treated with microwaves, $t_{15}-$ milk samples treated for 15 seconds with microwaves, $t_{30}$ - milk samples treated for 30 seconds with microwaves, $t_{45}-$ milk samples treated for 45 seconds with microwaves, $t_{60}$ - milk samples treated for 60 seconds with microwaves and $t_{120}$ - milk samples treated for 120 seconds with microwaves. Microwave heating was carried out using a Hansa AMM 21 E80GH microwave oven at electrical power of $800 \mathrm{~W}$.

The samples were then analyzed via infra red technology with the device called Lactoscope FTIR, a spectrophotometer from Delta Instruments. The concentrations of fat, protein, dry substance and lactose and also the density, in $\mathrm{g} / \mathrm{ml}$, were determined. The results were then statistically processed in Microsoft Office Excel using the indicators: average $(\mathrm{Xm})$, standard deviation $(s)$, coefficient of variation $(V \%)$ and correlation coefficient $(r)$ and the Student's $t$-test.

\footnotetext{
$\uparrow$ Presented at the $10^{\text {th }}$ International Symposium and Summer School on Bioanalysis within the CEEPUS Network CII-HU-001004-0910, Zagreb, Croatia, July 2010.

* Author to whom correspondence should be addressed. (E-mail: codre_anca@yahoo.com)
} 


\section{RESULTS AND DISCUSSION}

The standard deviation and the coefficient of variation applied to the obtained averages of the data showed that these have a high degree of representativity.

The averages of fat, protein, dry substance and lactose concentrations decreased during the microwave exposure while the density averages increased as we can see in Table 1.

But the variation of these parameters was not constant during the microwave treatment and we could observe that during the first 3 time intervals the variation was similar and for the next 3 intervals it was also allied. In order to see the moment in which the variation dynamic is changing we determined a series of critical points. Thus, we applied the linear regression and so we modelled the variation corresponding to the first 3 intervals by the equation: $y=a_{1}+b_{1} x$ and the variation for the next 3 intervals by the equation: $y=a_{2}+b_{2} x$, were $y$ is the studied parameter and $x$ is the corresponding time interval.

To verify the intensity of the connection between $x$ and $y$, we determined the corresponding correlation coefficients. After testing these coefficients with the Student's $t$-test, we established that between $x$ and $y$ there is a significant connection because the correlation coefficients are statistically eloquent.

The critical points were determined by the graphical intersection of the 2 lines characterised by the 2 equations presented above as one can see in Figures 1-5.

From the graphics we could determine the critical points characterized by critical $y$ and critical $x$, which values are presented in Table 2.

As one can observe in table 2, the critical value of the fat concentration obtained after $28.18 \mathrm{~s}$ was $2.59 \%$, the critical value of the dry substance concentration obtained after $30.01 \mathrm{~s}$ was $10.9 \%$, the critical value of the protein concentration obtained after $32.09 \mathrm{~s}$ was $3.27 \%$, the critical value of the lactose concentration obtained after $32.96 \mathrm{~s}$ was $4.45 \%$ and the critical value of the density obtained after $35.33 \mathrm{~s}$ was $1.03 \mathrm{~g} / \mathrm{ml}$.

Table 1. The physical-chemical parameters averages depending on the time exposure

\begin{tabular}{|c|c|c|c|c|c|}
\hline $\begin{array}{c}\text { Time } \\
\text { exposure }\end{array}$ & $\begin{array}{l}\text { Xm } \\
\text { (fat) }\end{array}$ & $\begin{array}{c}\mathrm{Xm} \\
\text { (protein) }\end{array}$ & $\begin{array}{c}\mathrm{Xm} \\
\text { (density) }\end{array}$ & $\begin{array}{c}\mathrm{Xm} \\
\text { (dry substance) }\end{array}$ & $\begin{array}{c}\mathrm{Xm} \\
\text { (lactose) }\end{array}$ \\
\hline $\mathrm{s}$ & $\overline{\%}$ & $\%$ & $\mathrm{~g} \mathrm{ml}^{-1}$ & $\%$ & $\%$ \\
\hline 0 & 2.9900 & 3.5770 & 1.0294 & 12.2940 & 5.1680 \\
\hline 15 & 2.6590 & 3.4100 & 1.0295 & 11.3600 & 4.7360 \\
\hline 30 & 2.6160 & 3.3000 & 1.0297 & 11.0000 & 4.5490 \\
\hline 45 & 2.5910 & 3.2680 & 1.0301 & 10.9090 & 4.4450 \\
\hline 60 & 2.5590 & 3.2630 & 1.0307 & 10.8760 & 4.4390 \\
\hline 120 & 2.5390 & 3.2470 & 1.0330 & 10.8670 & 4.4250 \\
\hline
\end{tabular}

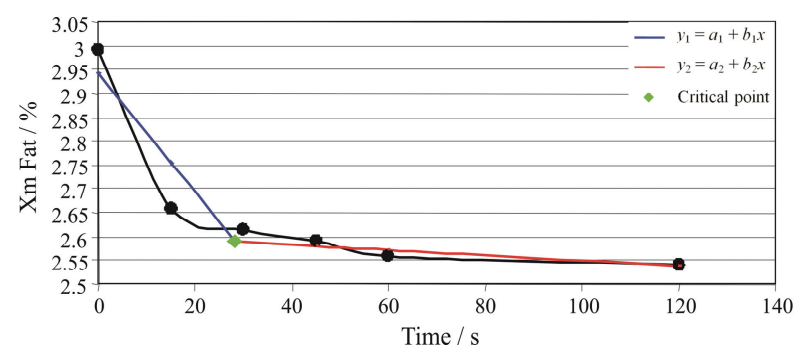

Figure 1. The critical point corresponding to $y$ critical protein.

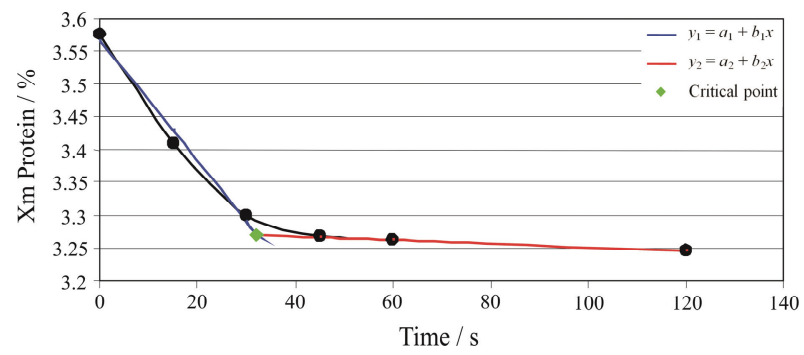

Figure 2. The critical point corresponding to $y$ critical protein.

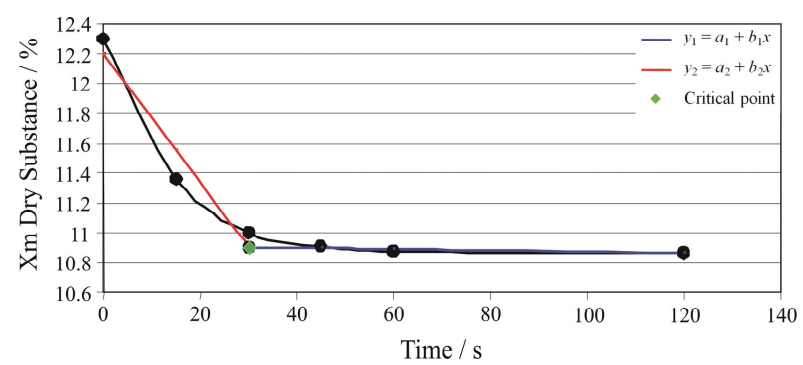

Figure 3. The critical point corresponding to $y$ critical dry substance.

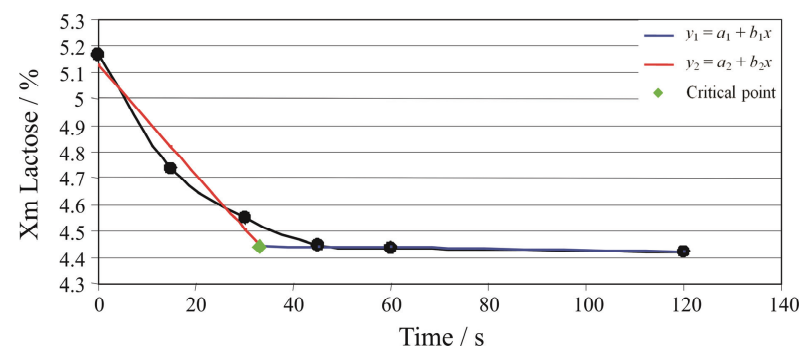

Figure 4. The critical point corresponding to $y$ critical lactose.

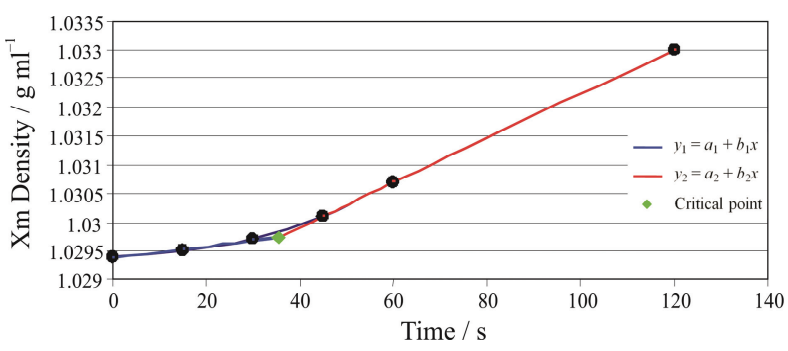

Figure 5. The critical point corresponding to $y$ critical density. 
Table 2. The critical values critical $y$ and critical $x$ obtained from the above graphics and the average of the critical $x$ values

\begin{tabular}{ccc}
\hline Parameter & Critical $y$ & Critical $x, \mathrm{~s}$ \\
\hline Fat $/ \%$ & 2.59 & 28.18 \\
Dry substance / \% & 10.90 & 30.01 \\
Protein / \% & 3.27 & 32.09 \\
Lactose / \% & 4.45 & 32.96 \\
Density / g ml ${ }^{-1}$ & 1.03 & 35.33 \\
& & \\
Average, Xm & & $\mathbf{3 1 . 7 1 0 0}$ \\
Standard deviation, $s$ & & 2.7400 \\
Coefficient of variation, $V(\%)$ & & 8.65000 \\
\hline
\end{tabular}

To find out the moment when a milk sample exposed to the microwaves action undergoes the first more significant alteration of its physical-chemical composition, we determine the average of the critical $x$ values, the standard deviation and the coefficient of variation, as one can see also in Table 2 .

According to the previously table, the critical time moment from which the microwave treated milk sample physical-chemical composition starts to suffer pronounced changes is $31.71 \mathrm{~s}$, with a standard deviation of 2.74. The value of $8.65 \%$ of the coefficient of variation being close to zero indicates a low variation of the studied values showing that the calculated average of the critical $x$ has a high level of representativity.

\section{DISCUSSION}

From the results part one can see that the averages of fat, protein, dry substance and lactose concentrations decreased during the microwave exposure while the density averages increased. These variation dynamics correspond to the data revealed in the specialized literature.

Milk lipids may undergo chemical and physical changes during processing and storage such as auto oxidation and formation of trans fatty acids ${ }^{11}$ and this fact may be an explanation for the decreasing content of fat in our milk samples. Al-Rowaily in 2008, obtained in his study a significantly increase in the levels of the oxidation parameters (thiobarbituric acid and peroxide value) for the milk treated with microwaves. Oxidation can also be induced by reactive oxygen species and free radicals that alter biomolecules and damage cell components yielding peroxides, alcohols, aldehydes and ketones. $^{12}$ So, lipids oxidation includes fatty acid oxidation and generates compounds that affect food quality and even nutrition and food safety. ${ }^{13}$ Also, Salamon et al. in 2007 stated that the microwave treatment per- formed for 2 and 8 minutes reduced proportion of the cis-configurated oleic acid and increased proportion of the trans-configurated elaidic acid formed from the former by izomerization to a significant extend. This decrease and increase, respectively, do not reach such extend that could affect the healthy nutrition.

The decreasing of the protein concentration can be explained by the fact that the whey protein sulfhydryl groups, typically buried within the core of the protein structure, are exposed to the surface because of heating. Furthermore, protein sulfhydryl groups may be formed because of hydrolysis or $\beta$-elimination of disulfide bonds during thermal treatment. ${ }^{15} \beta$-lactoglobulin, a major protein component of the whey fraction is often involved in these processes. ${ }^{16}$ Also, Clare et al. (2005) showed that the microwave treatment of milk increased concentration of "free" protein $\mathrm{SH}$ groups which are available for participation in subsequent oxidative reactions and ultimately contribute to the production of reactive oxygen species, such as singlet oxygen and hydroxyl radicals which can induce lipids oxidation as we discussed before concerning the variation of the fat concentration. Previously, others noted a low degree of whey protein denaturation, specifically $\beta$-lactoglobulin, after application of continuous microwave treatment using both cow and goat milk. ${ }^{18}$

Bohr and Bohr in 2000 suggested that microwave treatment could athermally affect the kinetics of the $\beta$ lactoglobulin folding process. Also, some of the hypotheses behind athermal effects of microwave heating suggest that microwave radiation may change the solvent properties of water. ${ }^{20}$

Data on the influence of microwave heating on the isomerisation and racemisation of amino acids have been published in the recent years. Studies applied on whole and skim milk was conducted by Petrucelli and Fisher (1994). They heated whole and skim milk samples for 10 minutes in a microwave oven at medium power or in a hot water bath at $80{ }^{\circ} \mathrm{C}$ and determined $\mathrm{D}$ aspartate and D-glutamate. They found no significant difference in the concentrations of these D-amino acids between the conventionally heated and microwave heated milks; both induced $<0.25 \%$ more racemization when compared to the control samples. Also, according to Fritz et al. (1994), the percentage of free D-proline was higher in conventionally-treated than in microwavetreated milk. These experiments clearly showed that microwave heating of milk under normal domestic conditions does not induce significant changes in their protein amino acids. The energy associated with microwave radiation is lower to that needed to break chemical bonds. ${ }^{10}$

Protein content can also decrease during the microwave exposure due to the fact that protein can be involved in the Maillard reaction together with the lactose. Among the proteins, the lysine is the most impli- 
cated in this reaction and its diminution in time became a nutritional indicator for the appreciation of the heat treatments effects on food. ${ }^{23}$

The explanation for the decreasing lactose concentration under the microwave treatment of the milk samples could be the fact that lactose, being a reducing disaccharide, can be involved in the Maillard reaction and during this reaction's first stage lactose is isomerised in lactulose. The condensation reactions between sugars and amino acids are known as Amadori rearrangements and always lead to final brown products usually indicated as melanoidins and also to an extremely variable number of intermediates (lactulose, furosine). The sequence of these successive reactions and products are generally defined as Maillard reaction. $^{24}$ It should be noted that there is relatively little information with respect to Maillard reactivity in microwave milk products. ${ }^{17}$ In one report, Villamiel et al. (1996) detected lactulose levels lower than $5 \mathrm{mg} / 100$ $\mathrm{ml}$ for the microwave treatment at $70{ }^{\circ} \mathrm{C}$ for 30 minutes, a level similarly to the conventional heating and a higher level of lactulose for the microwave treatment at 100-120 ${ }^{\circ} \mathrm{C}$ compared to the conventional heating, a finding attributed to the uneven heating in the microwave oven and to the fact that samples were heated in closed Teflon vessels.

Meissner and Erbersdobler (1996) tested the impact of microwave cooking on the formation of early Maillard products, including lactulose, using milk as a test system. The results failed to produce a significant difference between the microwave and the conventional cooking methods.

The increasing values of the density can make us conclude that the samples suffered a concentration process, mostly during the second minute of the experiment. This dryness phenomenon can be responsible for the susceptibility of the lipid oxidation process ${ }^{1}$ previously discussed.

The decreasing values of the dry substance are a confirmation of the fact that the samples lost quantitatively: water, fat, protein and lactose from their composition, processes demonstrated before. Also, the decreasing values of the dry substance can be influenced by the modifications that can appear concerning the vitamin content of the samples.

In 1996, Sieber et al. made a review about the heat treatment of milk in domestic microwave ovens and took into account also the influence of microwave heating on several vitamins in cow milk. So, Demel et al. (1990) found no loss of vitamin A, $\beta$-carotene and vitamin B1 or B2 in microwave-treated pasteurized milk and a loss of approximately $17 \%$ for vitamin $\mathrm{E}$ and $36 \%$ for vitamin C. Vitamin A was reduced slightly in milk (1.5 or $3.5 \%$ milk fat) heated to 80 to $90{ }^{\circ} \mathrm{C}$ on a hotplate or microwaved for 4, $5 \mathrm{~min}$, regardless of the heat source. ${ }^{27}$ Ac- cording to Sieber et al. (1993) vitamin B1 was not diminished in the upper and lower parts of microwave-treated milk and in stirred or unstirred milk. In both cases, the content of vitamin $\mathrm{C}$ was reduced. Hertel and Blanc (1992) found that the folic acid content of microwave treated milk was reduced compared to raw milk, but was only slightly lower than in pasteurized milk.

In 2000, Sierra et al. studied the effect of continuous-flow microwave heating of milk on the stability of vitamins B1 and B2 and the results indicate that continuous-flow microwave heating of milk at high temperature does not offer any advantage with respect to the vitamin $\mathrm{B} 1$ and $\mathrm{B} 2$ retention compared with a conventional heating process having the same heating, holding and cooling times.

\section{CONCLUSION}

The present study examined the effects of microwave treatment on some physical-chemical characteristics of the raw milk. The originality of the study consisted in the fact that we used reduced periods of time exposure, from 15 seconds to 2 minutes and unclosed vessels.

The averages of fat, protein, dry substance and lactose concentrations decreased during the microwave exposure while the density averages increased. Their variation was not constant but similar for the first 3 intervals and also for the next 3 intervals. After modelling the 2 different variations by linear regression we obtained by graphical intersection critical points for all the studied parameters. These critical points are characterized by critical $y$, meaning the studied parameter and critical $x$, the corresponding time interval.

We determined an average of $31.71 \mathrm{~s}$ of the critical $x$ values, corresponding to the moment when a milk sample exposed to the microwaves action undergoes the first more significant alteration of its physical-chemical composition.

\section{REFERENCES}

1. Meshref and A. Al-Rowaily, Pak. J. Nutr. 7 (2008) 118-125.

2. E. Valero, J. Sanz, and I. Martinez-Castro, Food Chem. 66 (1999) 333-338

3. R. A. Heddleson and S. Doores, J. Food Protect. 57 (1994) 1025-1037.

4. S. N. Aktas and M. Ozilgen, LWT - Food Sci. Technol. 25 (1992) 422-425.

5. A. Medrano, A. Hernández, M. Prodanov, and C. VidalValverde, Lait 74 (1994) 153-159.

6. M. Villamiel, N. Corzo, I. Martínez-Castro, and A. Olano, Food Chem. 56 (1996) 385-388.

7. R. López-Fandiño, M. Villamiel, N. Corzo, and A. Olano, J. Food Protect. 59 (1996) 889-892.

8. K. Meissner and H. F. Erbesdobler, J. Sci. Food Agric. 70 (1996) 307-310.

9. M. Villamiel, R. López-Fandiño, and A. Olano, Milchwissenschaft 51 (1997) 674-677. 
10. R. Sieber, P. Eberhard, and P. U. Gallmann, International Dairy Journal 6 (1996) 231-246.

11. M. Semma, Journal of Health Science 48 (2002) 7-13.

12. C. K. B. Ferrari, Biologia (Bratislava) 55 (2000) 581-590.

13. F. Pop and M. Rus, Carpathian Journal of Food Science and Technology I (1) (2009) 17-24.

14. R. V. Salamon, K. Loki, S. Salamon, P. Sara, B. Albert, Z. Mándoki, J. Csapo, and A. Györi, Agriculture: Scientific and Professional Review, Croatia 13 (1) (2007) 188-191.

15. P. S. Patrick and H. E. Swaisgood, J. Dairy Sci. 59 (1976) 594 600.

16. D. M. Mulvihell and J. E. Kinsella, Food Technology 41(1987) 102-107.

17. D. A. Clare, W. S. Bang, G. Cartwright, M. A. Drake, P. Coronel, and J. Simunovic, J. Dairy Sci. 88 (2005) 4172-4182.

18. M. Villamiel, R. López-Fandiño, N. Corzo, and A. Olano, Food Chem. 58 (1997) 49-52.

19. H. Bohr and J. Bohr, Phys. Rev. E: Stat., Nonlinear, Soft Matter Phys. 61 (4) (2000) 4310-4314.

20. Asher Shazman, S. Mizrahi, U. Cogan, and E. Shimoni, Food Chem. 103 (2007) 444-453.
21. L. Petrucelli and G. H. Fisher, J. Am. Coll. Nutr. 13 (1994) 209 210

22. P. M., Fritz, Zagon, Jutta, L. I. Dehne, and K. W. Bögl, Lebensmittelchemie 48 (1994) 51.

23. T. Florea, Chimia alimentelor, vol. 2, Ed. Academica, Galati, 2001,360

24. F. Mazzei, F. Botrè, G. Favero, E. Podestà, and C. Botrè, Microchem. J. 91 (2009) 209-213.

25. K. Meissner and H. F. Erbersdobler, J. Sci. Food Agric. 70 (3) (1996).

26. S. Demel, I. Steiner, J. Washtittl, and G. Kroyer, Z. Erniihrungswiss. 29 (1990) 299-303.

27. K. Wagner, H. Graf, G. Schaarmann, and G. Flachowsky, Einfluss von Kochen und Mikrowellenbehandlung auf den Vitamin-A-Gehalt von Trinkmilch. In Vitamine und weitere Zusatzstoffe bei Mensch und Tier, Flachowsky, G., Schubert, R. eds, Friedrich-Schiller-Universittit, Jena, 1993, 49-52.

28. R. Sieber, P. Eberhard, and W. Strahm, Ern\&hrzmg 17 (1993) 83-6.

29. B. H. Blanc and U. Hertel, Journal Franz Weber 5-10 (19) 1992.

30. I. Sierra and C. Vidal-Valverde, Lait 80 (2000) 601-608. 